\title{
A Study on Highly Sensitive C-Reactive Protein (Hs-CRP) in Patients with Bronchial Asthma
}

\author{
Md. Haroon Ur Rashid ${ }^{1}$, Md. Rezaul Karim Chowdhury², Md. Ehsanul Huq ${ }^{3}$, \\ Shamimur Rahman ${ }^{4}$, Nelson Taposh Mondal ${ }^{5}$
}

\begin{abstract}
Background: Asthma is a chronic inflammatory disorder of the airways. Relevance of highly sensitive $C$-reactive protein ( $h s-C R P$ ), an acute phase reactant and a sensitive marker of low-grade systemic inflammation in bronchial asthma has not been fully studied. Objectives: Reported studies have found an inverse relationship between lung function and markers of systemic inflammation. The aim of this study was to clarify the relationship between serum level of $h s-C R P$ and bronchial asthma. Materials and method: In this study, hs-CRP was measured in 60 patients with asthma and 40 healthy control subjects. Of all asthmatics, 39 patients had partially controlled and uncontrolled asthma and 21 patients had asthma during exacerbation. Results: Highly sensitive CRP was significantly higher $(p<0.000)$ in asthmatic patients as compared to the control group. In asthmatics with exacerbation, serum hs-CRP was significantly higher than in partially controlled and uncontrolled asthmatic patients $(p<0.006)$ and control subjects $(p<0.0001)$. Conclusion: Serum hs-CRP may be a non specific marker of asthma and its exacerbation.
\end{abstract}

Keywords: Atopic asthma; non atopic asthma; acute severe asthma; hs-CRP.

Delta Med Col J. Jul 2018;6(2):62 - 67

\section{Introduction}

Asthma is a chronic inflammatory disease of large, small and medium airways with typical symptoms (cough, wheeze, breathlessness, chest tightness) and airway narrowing that is partially or completely reversible either spontaneously or by treatment associated with increased airway responsiveness to a variety of stimuli. ${ }^{1}$ The prevalence of asthma increased steadily worldwide over the last several decades. Current estimates suggest that asthma affects 300 million people worldwide, with a predicted additional 100 million people to be affected by 2025 and approximately

1. Associate Professor, Dept. of Pulmonology, Enam Medical College \& Hospital, Savar, Bangladesh.

2. Associate Professor, Dept. of Haematology, Enam Medical College \& Hospital, Savar, Bangladesh.

3. Associate professor, Dept. of Community Medicine, Delta Medical College, Dhaka, Bangladesh.

4. Associate professor, Dept. of Nephrology, Enam Medical College \& Hospital, Savar, Bangladesh.

5. Associate professor, Dept. of Medicine, Enam Medical College \& Hospital, Savar, Bangladesh.

Correspondence: Dr. Md. Haroon Ur Rashid. e-mail: rkchow71@gmail.com 
250000-34500 people die per year from the disease. According to first National Asthma Prevalence Study (NAPS) 1999, in Bangladesh about 7 million people had been suffering from current asthma (at least 3 episodes of asthma attack in last 12 months) at that time. This disease affects approximately $7 \%$ of population of the United States and 5\% of the population of the United Kingdom. Canada, Australia and New Zealand have rates about $14 \%$ to $15 \% .^{2}$

Bronchial asthma is classified pathophisiologically into two types, atopic and non atopic asthma. ${ }^{2}$ According to the level of control, asthma is classified into three types, well controlled asthma, partially controlled asthma and uncontrolled asthma. ${ }^{1}$

C-reactive protein (CRP) is a major inflammation sensitive plasma protein in humans. Its synthesis by the liver is regulated to a large extent by the pro-inflammatory cytokine interleukin 6 (IL-6). ${ }^{3}$ The measurement of CRP level in the blood is simple and has been used for decades in clinical practice to follow the progression of inflammatory processes. ${ }^{4}$ Reduced lung function has been associated with various inflammation sensitive plasma proteins..$^{5,6}$

Standard assays for CRP lack the sensitivity needed to determine the levels of inflammation and thus, clinical utility of standard CRP evaluation is extremely limited. Recent improvements have resulted in a new generation of highly sensitive assays that can detect the CRP at levels 100-fold lower than the earlier assays. ${ }^{7}$ CRP determined using a highly sensitive assay is referred to as highly sensitive CRP (hs-CRP). Using hs-CRP, assessment of conditions indicative of chronic, low-grade inflammation is now possible. A positive association has been reported between raised hs-CRP levels and current asthma, respiratory impairment and bronchial hyper-reactivity in several studies. ${ }^{5,8}$
There is an association between increased hs-CRP levels and non-atopic asthma even when adjusted for body weight, but not so between hs-CRP and atopic asthma. ${ }^{9}$ An association has been reported between elevated hs-CRP levels and respiratory symptoms, such as wheeze, attack of breathlessness and nocturnal cough. ${ }^{10}$

The aim of our study was to evaluate the significance of hs-CRP in asthma cases.

\section{Materials and method}

\section{Patients}

The study was performed on asthmatic patients and healthy non asthmatic controls. In the present study hs-CRP was determined in 60 patients with asthma and 40 healthy controls. Of all the asthmatics, 39 had partially controlled asthma and 21 had asthma with exacerbation, 16 patients had atopic and 44 patients had non atopic asthma, 09 patients were on regular inhaled corticosteroids (ICS) and 51 patients were not on inhaled corticosteroids (ICS). The subjects included in the study were the patients from outdoor and indoor of Enam Medical College and Hospital (EMCH), Savar, Bangladesh.

Patients were excluded if they were smokers, obese, had respiratory infection within the month preceding the study, a rheumatologic illness, malignancy, diabetes, heart failure, history of venous thromboembolism, coronary heart disease and liver or kidney disease. Normal volunteers were also enrolled in the study as controls. None of them had any previous history of lung or allergic disease and were not using any medication. At enrolment, they all underwent full clinical examination, pulmonary function tests, and blood sampling. Normal volunteers had normal lung function tests (FEV1>80\%) and normal IgE level. Those with high IgE were considered as atopic asthma. 
Partially controlled asthma, uncontrolled asthma and exacerbation of asthma were defined according to guidelines.

The sampling was performed during the period from May 2017 to December 2017.

\section{Determination of serum hs-CRP}

Serum hs-CRP was determined using an immunofluorescence assay (hs-CRP Fast Test Kit) by Getein Biotech, Inc, UK. The test was performed according to the manufacturer's instructions.

\section{Statistical Analysis}

The values are reported as mean $\pm \mathrm{SD}$ and $95 \%$ confidence interval. For statistical analysis between groups independent sample $t$ test was used. The levels of each marker were compared between the study groups and control group, using SPSS 16 computer package. $p$ values of $<0.05$ were considered significant.

\section{Results}

Significantly higher serum hs-CRP (in $\mathrm{mg} / \mathrm{L}$ ) was found $(\mathrm{p}<0.000)$ in asthmatic patients $(\mathrm{Mean} \pm \mathrm{SD}=$ 11.67 \pm 1.16 ; Median=7.75) when compared to the control group (Mean $\pm \mathrm{SD}=1.53 \pm 1.38$; Median=1.00). In asthmatics with exacerbation, serum hs-CRP was significantly higher $($ Mean $\pm \mathrm{SD}=20.16 \pm 1.30 ; \quad$ Median=18.00) than control subjects $($ Mean $\pm \mathrm{SD}=1.53 \pm 1.38$; Median=1.00). In asthmatics on regular ICS, serum hs-CRP was significantly higher (Mean $\pm \mathrm{SD}=2.96 \pm 2.94 ; \quad$ Median=2.00) than control subjects $($ Mean $\pm \mathrm{SD}=1.53 \pm 1.38$; Median=1.00). In asthmatics without regular ICS, serum hs-CRP was significantly higher (Mean $\pm \mathrm{SD}=13.21 \pm 1.19 ; \quad$ Median=9.00) than asthmatics on regular ICS (Mean $\pm \mathrm{SD}=2.96 \pm 2.94$;
Median=2.00). In atopic asthma patients serum hs-CRP was significantly higher (Mean $\pm \mathrm{SD}=3.53 \pm 2.37$; Median=2.7) than normal control (Mean $\pm \mathrm{SD}=1.53 \pm 1.38$; Median=1.00). In non atopic asthma hs-CRP level is higher (Mean $\pm \mathrm{SD}=14.63 \pm 1.22 ; \quad$ Median=11.1) than atopic patients (Mean $\pm \mathrm{SD}=3.53 \pm 2.37$; Median=2.7). In acute severe asthma patients serum hs-CRP was significantly higher (Mean $\pm \mathrm{SD}=20.16 \pm 1.30 ; \quad$ Median=18.00) than inadequately controlled asthma (Mean $\pm \mathrm{SD}=7.1$ \pm 7.62 ; Median=6.0) $(\mathrm{p}<0.000)($ Table I).

Table I: Distribution and comparison of hs-CRP level between different groups

\begin{tabular}{|c|c|c|c|}
\hline Group & Mean \pm SD & Median & p value* \\
\hline Asthmatic $(\mathrm{n}=60)$ & $11.67 \pm 1.16$ & 7.75 & \multirow{2}{*}{0.000} \\
\hline Control $(n=40)$ & $1.53 \pm 1.38$ & 1.00 & \\
\hline Acute asthma $(\mathrm{n}=21)$ & $20.16 \pm 1.30$ & 18.00 & \multirow{2}{*}{0.000} \\
\hline Control $(\mathrm{n}=40)$ & $1.53 \pm 1.38$ & 1.00 & \\
\hline Asthmatic on ICS (n=09) & $2.96 \pm 2.94$ & 2.00 & \multirow{2}{*}{0.000} \\
\hline Control $(n=40)$ & $1.53 \pm 1.38$ & 1.00 & \\
\hline Asthmatic on ICS (n=09) & $2.96 \pm 2.94$ & 2.00 & \multirow{2}{*}{0.000} \\
\hline Asthmatic not on ICS $(n=51)$ & $13.21 \pm 1.19$ & 9.0 & \\
\hline Atopic $(\mathrm{n}=16)$ & $3.53 \pm 2.37$ & 2.7 & \multirow{2}{*}{0.000} \\
\hline Non atopic $(n=44)$ & $14.63 \pm 1.22$ & 11.1 & \\
\hline Atopic $(\mathrm{n}=16)$ & $3.53 \pm 2.37$ & 2.7 & \multirow{2}{*}{0.000} \\
\hline Control $(\mathrm{n}=40)$ & $1.53 \pm 1.38$ & 1.00 & \\
\hline Partially controlled $(\mathrm{n}=39)$ & $7.1 \pm 7.62$ & 6.0 & \multirow{2}{*}{0.000} \\
\hline Acute asthma $(\mathrm{n}=21)$ & $20.16 \pm 1.30$ & 18.00 & \\
\hline
\end{tabular}

*p value from Mann-Whitney U test

\section{Discussion}

The C-reactive protein (CRP), so named for its capacity to precipitate the somatic C-polysaccharide of Streptococcus pneumoniae is an exquisitely sensitive though non-specific marker of acute inflammation and tissue damage. ${ }^{11}$ The CRP belongs to a family of molecules called the pentraxins. Structurally CRP is composed of five identical non-glycosylated polypeptide subunits (pentraxin; penta=five, ragos=berries), each $23 \mathrm{kDA}$ in mass, held together by non-covalent bonds to form a disc-like 
pentagonal ring. ${ }^{12,13}$ The CRP is predominantly synthesized in the liver and is regulated by pro-inflammatory cytokines, primarily the tumour necrosis factor-alpha and interleukin-6 (IL-6). During an acute-phase response, there is a rapid increase in the production of CRP (10,000-fold), resulting in the release of elevated quantities into the circulation. The plasma half-life of CRP is approximately 19 hours. Although its function is still unclear, the CRP may serve as a general scavenger protein and play an important role in opsonisation, phagocytosis, and cell-mediated cytotoxicity. The CRP can also act as a potent proinflammatory agent and activates the classical complement cascade by binding directly to the complement fragment C1q. ${ }^{13,14}$

C-reactive protein (CRP) is a highly sensitive marker of inflammation, infection and tissue damage. A positive relationship has been reported between raised CRP levels and current asthma, respiratory impairment, and bronchial responsiveness. ${ }^{5,8,15-19}$ However, some studies deny any kind of relationship between CRP levels and spirometry indices such as FEV1 or IgE in asthma patients. ${ }^{20,21}$

In our study hs-CRP level was found much higher in asthmatic patients than normal control similar to that of the studies by Eizadi Mojtaba and colleagues, ${ }^{22}$ Takemura $\mathrm{M}$ et al., ${ }^{14}$ and Olafsdottir et al. ${ }^{10}$, who found that hs-CRP is a useful marker in bronchial asthma. Highly sensitive-CRP has been demonstrated by Obaidi et al. ${ }^{23}$ to be higher in asthmatics as opposed to controls. The majority of patients with reduced FEV1 have asthma, chronic obstructive pulmonary disease (COPD), or fibrotic lung disease. ${ }^{18}$ In these conditions, cytokines are over expressed in lung tissue, potentially resulting in systemic low-grade inflammation. ${ }^{18,24,25}$ Our findings support the hypothesis that not only local but also systemic inflammation exists in bronchial asthma.
Many previous studies have shown that patients with atopic and non atopic asthma differ in many aspects, including responsiveness to cold air, response to adenosine monophosphate (AMP), levels of nitrogen oxide (NO) in expired air and the level of eosinophilic inflammation in the airways. ${ }^{26-28}$ Our results show a stronger association between increased hs-CRP and non-atopic asthma, than between hs-CRP and atopic asthma which further emphasizes the difference between these two subgroups of asthma. This finding is similar to that of Olafsdottir et al. ${ }^{10}$ and Sahoo et al. ${ }^{9}$ The increased hs-CRP levels in non atopic asthma support the theory that, in non-atopic asthma, there is not only a local but also an ongoing systemic inflammatory process. The present study also showed that the patients with asthma not on ICS has increased serum hs-CRP levels compared to those on ICS. Furthermore, in patients on ICS treatment, serum hs-CRP levels are more than healthy controls. It is likely that the ICS, which has well characterized anti-inflammatory properties, used in these patients might have reduced serum hs-CRP. ${ }^{14}$

Balakrishnan et al. ${ }^{29}$ concluded that significant positive correlation of hs-CRP with exacerbation rates and significant negative correlation of hs-CRP and FEV1 are seen during remission. Thus hs-CRP levels during remission may be used as a marker for predicting future exacerbations in asthmatics. ${ }^{30}$ Kony et al. ${ }^{5}$ in a population-based study showed associations of increased levels of serum hs-CRP with a high frequency of airway hyper responsiveness and FEV1 among subjects without heart disease. Furthermore they observed that CRP levels were significantly higher during exacerbations than in stable asthmatic patients. A study by Jousilhti et al. ${ }^{8}$ demonstrated that asthma increased gradually with increasing hs-CRP. In the present study, asthma exacerbation was strongly related to higher hs-CRP levels, whereas partially 
controlled, uncontrolled asthma and control subjects had lower levels of hs-CRP supporting the findings of Obaidi et al. ${ }^{23}$ and Mahmoud et al. ${ }^{31}$ who concluded following a study on 235 cases that hs-CRP rises and falls with the severity of asthma. Thus hs-CRP measurement can be helpful in predicting asthma control and treatment response.

Increase in serum hs-C-reactive protein levels measured by high-sensitivity assays may be associated with airflow obstruction in acute asthma, and may be useful as a sensitive marker and a diagnostic tool for detecting and monitoring airway inflammation in patients with acute asthma. Subsequently, hs-CRP can be considered as a surrogate marker of airway inflammation in bronchial asthma.

\section{Limitations-}

- Sample size was small.

- Patients with stable asthma were not included.

- Follow up hs-CRP level among patients with acute exacerbation was not done.

\section{References}

1. Asthma. Bangladesh Lung Health Manual. 1st ed. Vol 1. BLF. Oct 2009.

2. National Guidelines Asthma and COPD. 5th ed. Asthma Association of Bangladesh. Jan 2016.

3. Gillman B, Papachristodoulou DK, Thomas JH. Will's Biochemical Basis of Medicine. Oxford: Butterworth Heinemann; 2000.

4. Burtis CA, Ashwood ER. Tietz Textbook of Clinical Chemistry. 3rd ed. Philadelphia: Saunders Co; 1999.p.617-721.

5. Kony S, Zureik M, Driss F, Neukirch C, Leynaert B, Neukirch F. Association of Bronchial Hyperresponsiveness and Lung Function with C-Reactive Protein (CRP): A Population Based Study. Thorax. 2004;59:892-96.
6. Mendall MA, Strachan DP, Butland BK, Ballam L, Morris J, Sweetnam PM, et al. C-reactive Protein: Relation to Total Mortality, Cardiovascular Mortality and Cardiovascular Risk Factors in Men. Eur Heart J. 2000;21:1584-90.

7. Aziz N, Fahey JL, Detels R, Butch AW. Analytical Performance of a Highly Sensitive C-Reactive Protein-Based Immunoassay and the Effects of Laboratory Variables on Levels of Protein in Blood. Clin Diagn Lab Immunol. 2003;10:652-57.

8. Jousilahti P, Salomaa V, Hakala K, Rasi V, Vantera E, Palosuo T. The Association of Sensitive Inflammation Markers with Bronchial Asthma. Ann Allergy Asthma Immunol. 2002;89:381-85.

9. Sahoo RC, Acharya PR, Noushad TH, Anand R, Acharya VK, Sahu KR. A Study of High-Sensitivity C-Reactive Protein in Bronchial Asthma: Indian J Chest Dis Allied Sci. 2009;51:213-16.

10. Olafsdottir IS, Gislason T, Thjodleifsson B, Olaffson I, Gislason D, Jogi R, et al. C Reactive Protein Levels Are Increased in Non-Allergic but Not Allergic Asthma: A Multicentre Epidemiological Study. Thorax. 2005;60:451-54.

11. Pepys MB, Batz ML. Acute Phase Protein with Special Reference to C-Reactive Protein and Related Proteins (Pentaxins) and Serum Amyloid A Protein. Adv Immunol. 1983;34:141-212.

12. Thompson D, Pepys MB, Wood SP. The Physiological Structure of Human C-Reactive Protein and Its Complex with Phosphocholine. Structure. 1999;7:169-77.

13. Anderson GP. COPD, Asthma and C-reactive Protein. Eur Respir J. 2006;27:874-76.

14. Takemura M, Matsumoto H, Niimi A, Ueda $T$, Matsuoka H, Yamaguchi M, et al. High Sensitivity C-reactive Protein in asthma. Eur Respir J. 2006;27:908-12.

15. Ford ES. The Epidemiology of Obesity and Asthma. J Allergy Clin Immunol. 2005;115:897-909.

16. Cirillo DJ, Agrawal Y, Cassano PA. Lipids and Pulmonary in the Third National Health and Nutrition Examination Survey. Am J Epidemiol. 2002;55:842-48. 
17. Danesh J, Wheeler JG, Hirschfield GM, Eda S, Eiriksdottir G, Rumley A, et al. C-Reactive Protein and Other Circulating Markers of Inflammation in the Prediction of Coronary Heart Disease. N Eng J Med. 2004;350:387-97.

18. Mannino DM, Ford SS, Redd SC. Obstruction and Restrictive Lung Disease and Markers of Inflammation. Am J Med. 2003;114:758-62.

19. Gann WQ, Man SFP, Senthilselvan A, Sin DD. Association between Chronic Obstructive Pulmonary Disease and Systemic Inflammation: A Systematic Review and Meta Analysis. Thorax. 2004;59:574-80.

20. Ramirez D, Patel P, Casillas A, Cotelingam J, Bogas P, Bahna SL. Assessment of High Sensitivity C-Reactive Protein as a Marker of Airway Inflammation in Asthma. Ann Allergy Asthma Immunol. 2010;104(6):485-89.

21. Ebrahim R, Hassan E, Hossein A, Vajihe C, Armin R. Evaluation of High-Sensitivity C-Reactive Protein in Acute Asthma. Tanaffos. 2012;11(1):32-37.

22. Mojtaba E, Somayeh B, Payman A, Davood K. A Study of High-Sensitivity C-Reactive Protein in Relation to Respiratory Symptoms in Mild to Moderate Asthma. International Journal of Biosciences. 2011;1(5):83-88.

23. Obaidi AHA, Samarai AGMA, Jawad AKY, Janabi JMA. Association between C Reactive Protein and Asthma. Turkish Thoracic Journal. 2010;11:98-104.

24. Sin DD, Lacy P, York E, Man SF. Effects of Fluticasone on Systemic Markers of Inflammation in Chronic Obstructive Pulmonary Disease. Am J Respir Crit Care Med. 2004;170(7):760-65.
25. Sin DD, Man SF. Why Are Patients with Chronic Obstructive Pulmonary Disease at Increased Risk of Cardiovascular Diseases? The Potential Role of Systemic Inflammation in Chronic Obstructive Pulmonary Disease. Circulation. 2003;107(11):1514-19.

26. Ludviksdottir D, Janson C, Bjornsson E, Stålenheim G, Boman G, Hedenström H, et al. Different Airway Responsiveness Profiles in Atopic Asthma, Nonatopic Asthma, and Sjogren's Syndrome. BHR Study Group. Bronchial Hyperresponsiveness. Allergy. 2000;55:259-65.

27. Ludviksdottir D, Janson C, Hogman M, Hedenström H, Bjornsson E. Exhaled Nitric Oxide and Its Relationship to Airway Responsiveness and Atopy in Asthma. BHR Group. Respir Med. 1999;93:552-56.

28. Amin K, Ludviksdottir D, Janson C, Nettelbladt O, Björnsson E, Roomans GM, et al. Inflammation and Structural Changes in the Airways of Patients with Atopic and Nonatopic Asthma. BHR Group. Am J Respir Crit Care Med. 2000;162:2295-301.

29. Menon B, Nima1 G, Dogra V, Kaur C. C Reactive Protein as a Marker of Asthma Control. International Journal of Basic and Applied Medical Sciences. 2013;3(3):114-19.

30. Menon B, Kaur C, Kaushik R, Pandita. Evaluation of High Sensitivity C Reactive Protein in Patients of Bronchial Asthma and Its Correlation with Exacerbation Rate and Pulmonary Function. European Respiratory Journal. 2008;32(52):195s.

31. Monadi M, Firouzjahi A, Hosseini A, Javadian Y, Sharbatdaran M, Heidari B. Serum C-Reactive Protein in Asthma and Its Ability in Predicting Asthma Control, a Case Control Study. Caspian J Intern Med. 2016;7(1):37-42. 